\title{
6 \\ Faculty Understanding and Implementation of Internationalization and Global Citizenship
}

Cindy Hanson \& Barbara McNeil

University of Regina

This paper shares insights into how university faculty understand and integrate internationalization and global citizenship ideas into their pedagogical practices. The study worked with a broad base of faculty to come to an understanding of what it means for scholarship to embrace internationalization in teaching and then to explore ways of sharing that knowledge through pedagogical practices in the classroom. The results demonstrate faculty commitments to global citizenship, willingness to share teaching strategies, and ethicalconcerns about internationalization. Through this project the researchers hope to inform capacity to understand, develop, and deliver teaching strategies that enhance values associated with global citizenship.

\section{Background to the Study}

Cor the past two decades, educational institutions 1 across Canada have become increasingly involved in working toward internationalization. The strategic plan at the University of Regina, for example, addresses internationalization as a direction for growth. According to Knight (2008), internationalization is a "process of integrating an international, intercultural, and global dimension into the purpose, functions (teaching, research, and service), and delivery of higher education at the institutional and national levels" (p. xi). Although the implications for internationalization are many, our study, KnowledgeSharing for Improved Pedagogical Practices in Global Citizenship, asks what internationalization means for the scholarship of teaching and learning, particularly as it impacts the development of global citizenship.

The research asked the following questions:

1) How do faculty define pedagogies and teaching practices about global citizenship? and 2) How do faculty support and implement teaching for global citizenship and what kind of strategies do they use? This paper outlines the study methods and themes that emerged from the research, and presents several pedagogical practices used by faculty to enhance internationalization and global citizenship.

\section{Methodology}

Research methods included a focus group and semi- 
structured interviews. Through the researchers' personal contacts and extended networks, faculty were invited by electronic mediums to attend the focus group. The intent was to involve faculty from a range of disciplines, which ultimately included arts, social sciences, business administration, and education. Ten faculty members participated in the two-hour focus group; five of these faculty members agreed to be interviewed. Four additional faculty members, who were unable to attend the focus group, joined them. The focus group and interviews were recorded and transcribed, and then the data was read multiple times and sorted thematically by the researchers and a student research assistant. Several recurrent themes were identified from the analysis of data.

\section{Themes from the Research}

The following themes emerged from the research: 1) the role and responsibility of the university; 2) ethical concerns; 3) the value of taking a global citizenship approach; and 4) development of critical consciousness. In discussing the themes, participant quotations are sometimes used (with pseudonyms) to illustrate perspectives of the study participants.

\section{Institutional role and responsibility}

Although the university was generally commended for including internationalization in its strategic planning and core functions (a general trend noted by Childress (2009) and Green and Schonberg (2006), among others), several study participants questioned how extensive the consultations with faculty had been, what internationalization meant in practice to the institution, and the motivations behind pushes in this direction. Overall, study participants demonstrated a personal commitment to the practice of internationalizing their respective curricula. Nonetheless, they expressed concerns about the lack of supports for their efforts and the complexities of internationalizing while managing increasingly heavy academic workloads. A key study by Childress (2009) confirms that implementation of internationalization generally is carried out by faculty, and therefore, institutional investments of resources to support faculty efforts toward the operationalization of internationalization is central to its success

\section{Ethical concerns}

Stier (2004) suggests that universities use three perspectives with regard to internationalization: idealism, educationalism, and instrumentalism. Instrumentalists consider higher education a means to ensure economic growth or to transmit ideologies of governments, transnational corporations, or other interest groups. The faculty we interviewed predominantly exhibited and supported the first two categories suggested by Stier, but they were critical of instrumentalism. One faculty member said, "When I hear global citizenship...I hear responsibility, I hear participation, I hear justice, and I think what it encourages me to do is to... talk to students about why we are here, what is our effect on others?" (Janine). Such idealism, ethical orientation, and concern for self and others were contrasted with economic self-interest, which many perceived as the driving force behind internationalization. Again and again, faculty members brought forward normative discourses about market models as oppressive and competitive, such as illustrated in this example:

There is a school of thought that maintains that this interest by universities in internationalization is a money grab because foreign students are supposed to be paying differential fees. The question then is the issue of ethical responsibility. If you look at where these students are coming from (developing countries, for some of them), how ethical is it to charge them for whatever as a way of perhaps making up for shortfalls in government grants? (Alabie)

According to Alabie, the imperative for the internationalization of universities is economic self-interest which Matus and Talbert (2009) say is characteristic of northern universities which actively participate in neo-liberal practices linked to 
globalization. Generally, participants critiqued the way universities increasingly emphasized branding, profiling, and recruitment of foreign students without explicitly addressing "ethical responsibilities, and helping faculty and students make sense of those connections" (Keith).

Study participants understood how knowledge and power exercised through curricula and pedagogical practices could disrupt normative, hegemonic discourses about internationalization. Thus, many suggested teaching in ways that are intentionally critical in order to resist and disrupt the tendency to re-inscribe colonial relations of power.

\section{Global citizenship}

Karlberg (2008) suggests that global citizenship has become a "significant discursive construct" in the university and elsewhere (p. 310), and our research supported this notion. On the whole, faculty's understanding of global citizenship draws on discourses in which global citizenship involves "being empowered" and where citizens have responsibilities toward global relations, peace, environmentalism, and understanding the interconnectedness of issues. These understandings converge with Toh's (1996) ideas about global citizenship explained as "awareness of and commitment to social justice for marginalized groups, grassroots empowerment, nonviolent and authentic democracy, environmental care, and North-South relations based on principles of equity, respect and sharing" (p. 185). One participant, Rainy, explained that "now collectively, we've come together and realize we can put resources as a university towards endeavours that advance global citizenship" and that "[allow] us not only to design new courses but also to address some of the systemic injustices through that lens - citizenship lens." Another participant explained that through the emphasis on global citizenship, "we are no longer [operating] as one who serves the province in terms of citizenship, but as one who serves a global community. This is really broadening that sense of accountability but also empathy at a deeper level" (Joseph). These examples typify the inclusionary discourses of caring, social justice, equity, compassion, humanitarianism, and cosmopolitanism (Karlberg, 2008) that imbue notions of global citizenship within a transformative model of education (Hanson, 2010).

The participants in the study predominantly represented faculty in liberal arts disciplines and were not representative of faculty in hard disciplines, such as math and science, who Clifford (2009) says represent viewpoints that explain knowledge as fixed and less open to difference. This may explain why the majority of faculty in the study described characteristics of reflexivity, responsibility, and agency as desirable for global citizenship. Others, however, offered a more educationalist view where transformation was not the intent. Instead they expressed the view that internationalization is useful for offering students " a unique and enriching learning experience” (p. 92). These expressions stress the importance of personal learning through intercultural understanding. For instance, one participant stated that "there is always that culture component; students in every lesson are reading about culture, economy, and geography... they do some research about a country... and it is a good way to learn about the rest of the world" (Kirsty). Such views do not necessarily challenge power structures inherent in international relations, and the participants holding these views are less likely to intentionally promote critical consciousness in learning.

\section{Critical consciousness}

Many study participants referenced a vision of critical consciousness linked to Freire (1970), who suggests that transformation becomes possible when the awareness of one's position in the world becomes apparent - that is, "learning to perceive social, political and economic contradictions and to take actions" (p. 17). For some of those interviewed, this meant implementing strategies that oriented students to think about self and others through the construction of interdisciplinary courses about environmental ethics, global citizenship, international business, and international development. Faculty members explained that in such courses, emphasis is placed on knowing and understanding how actions in one locality affect citizens in another. For example, one participant said the process involves taking problems within communities and saying, "It's not just here 
in Saskatchewan...our day-to-day activities impact people in other places, like a developing country" (Dalton). The examination of connections between issues, people, and geographies was thus an important aspect of pedagogical practice for faculty in the study.

\section{Pedagogical Practices and Strategies}

Most study participants were grounded in pedagogical practices oriented toward social justice and challenging dominant knowledge systems, again a finding that does not concur with broader studies that distinguish differences between disciplines (Clifford, 2009). They spoke about using methods that linked students to local and global communities. Finally, they addressed the need to challenge Western ways of knowing and find culturally appropriate ways of addressing student issues and learning styles. Faculty advocated using a variety of instructional strategies. The use of small group work and invited speakers to represent different realities was reiterated frequently. It was viewed as a way of breaking isolation and engaging students who do not readily participate in large groups.

Faculty were critical of Eurocentric notions held by students and felt that by using examples which demonstrated 'other' realities and ways of doing things, some of these viewpoints might shift. The ways in which faculty addressed this problem differed; for example, some included different political and cultural representations in their curriculum. One faculty member used a simulation exercise wherein students simulate living in another culture for the duration of the semester. The students in that 'other' culture then come to understand how 'othering' operates and how it feels; for example, they experience visits from people representing dominant culture. Additionally a couple of faculty members investigated intercultural dialogue through digital networks linking students in different parts of the world to address ethical questions around global relations and the arts.

One faculty member had students trace the secret life of stuff thus enabling students to learn about the origins and pathways for items or foods found in North America, such as in the case of Tomasito (Ecumenical Coalition for Economic Justice, 1994). Similarly, case studies were used in several disciplines as a way of integrating local and global experiences. Faculty noted that case studies present dimensions of real life situations and provide a way of engaging students philosophically.

Another faculty noted the importance of using student experience as a starting place for actions. She explained the implementation of an exercise where she moves students into a circle (using principles of an Aboriginal talking circle), places a collection of objects on a cloth in the centre of the circle, and then has students select an object that reminds them of a story in their lives: the stories are then shared. Similarly, another faculty stated that for students to understand the world they live in, livelihood mapping is an important way to link issues to personal lives. Livelihood mapping explains the interconnections between resources and choices made by individuals. Rainy explains:

If you help them think about what their options are in a concrete way, then they can actually address some of the sustainability issues they observe about their own livelihoods and see areas where they can make changes and help others.

Using learning tools that assist students to understand current realities was deemed important. One faculty explained how he uses the board game Monopoly as a way of demonstrating how wealth is concentrated in society. In deconstructing the game, students were asked to name what the game's pieces represent, to discuss how concentration of wealth can lead to socioeconomic inequities, and to name the responsibilities that citizens have to change such disparities.

The focus group provided a dynamic platform wherein faculty shared their knowledge and classroom practices. Many expressed a yearning for more opportunities to conduct such an exchange. Through the examples provided, faculty demonstrated cross-disciplinary, collaborative, knowledge-sharing experiences aimed toward global citizenship. 


\section{Conclusion}

This small study supported the findings of previous studies (Childress, 2009; Dewey \& Duff, 2009) which suggested that internationalization is perceived as inevitable for universities and, hence, it is vital to broadly enlist the involvement of faculty in internationalization processes and to provide them with appropriate supports. Although skepticism among faculty members exists, the level of activity toward internationalizing curricula evident at the individual level in the area of teaching (Knight, 2004) points to the existence of considerable sympathy and support for understanding global citizenship as a shared responsibility. Similar to faculty perceptions in the study by Dewey and Duff (2009), the faculty we interviewed "desire clarity in faculty involvement and roles in internationalization at the institutional level” (p. 501). The study participants are cautious about conceptual and policy understandings at the institutional level, and they welcome increased involvement in university processes toward internationalization. Most of the study participants were particularly supportive of taking an ethical stance toward global citizenship - one that clearly articulates or challenges power inequities, and encourages the development of a critical consciousness among learners.

\section{References}

Childress, L. (2009). Planning for internationalization by investing in faculty. Journal of International and Global Studies, 1(1), 30-49.

Clifford, V.A. (2009) Engaging the disciplines in the discourse of internationalising the curriculum. International Journal for Academic Development, 14(2) 133-143.

Dewey, P. \& Duff, S. (2009). Reason before passion: Faculty reviews on internationalization in higher education. Higher Education, 58(4), 491-504.

Ecumenical Coalition for Economic Justice. (1994).
“Tomasito's guide to economic integration: A whirlwind tour with your guide Tomasito, the tomato" in Economic Integration of the Americas: An education and action kit. Toronto: Ecumenical Coalition for Economic Justice.

Freire, P. (1970). Pedagogy of the oppressed. New York: Continuum.

Green, M.F., \& Schoenberg, R. (2006). Where faculty live: Internationalizing the disciplines. Washington, DC: American Council on Education.

Hanson, L. (2010). Global Citizenship, global health, and the internationalization of curriculum: A study of transformative potential. Journal of Studies in International Education, 14, 70-88.

Karlberg, M. (2008). Discourse, identity, and global citizenship. Peace Review, 20, 310-320.

Knight, J (2004). Internationalization remodelled: Definitions, approaches and rationales. Journal of Studies in International Education, $8,5-31$

Knight, J. (2008). Higher education in turmoil: The changing world of internationalization. Rotterdam: Sense Pub.

Matus, C. \& Talburt S. (2009). Spatial imaginaries: Universities, internationalization, and feminist geographies. Discourse: Studies in the Cultural Politics of Education, 30(4), 515-527.

Stier, J. (2004). Taking a critical stance toward internationalization ideologies in higher education: Idealism, instrumentalism and educationalism. Globalization, Societies and Education, 2(1), 83-97.

Toh, S. (1996). Partnerships as solidarity: Crossing North-South boundaries. Alberta Journal of Educational Research, 42, 178-191. 
University of Regina. (2010). Mâmawohkamâtowin: Our work, our people, our communities. Unpublished Strategic Plan 2010-2014.

\section{Biographies}

Cindy Hanson is an Assistant Professor of Adult Education and Human Resource Development at the University of Regina. Her doctoral work at the University of British Columbia explored the pedagogical practices used by Canadians working globally in gender equality; she similarly worked as a development consultant for 15 years.

Barbara McNeil is an Associate Professor in Language and Literacy at the University of Regina. She has worked and taught in diverse international contexts.

Drs. Hanson and McNeil both sit on the Board of the Centre for International Education and Training at the University of Regina. They are the co-recipients of a President's Teaching and Learning Scholar Award from which this study emerges. 